\title{
Characteristics of Ultrasonically Enhanced Low-Temperature Thermal Regeneration of Powdered Activated Carbon: A Case Study of Acetone and Aniline
}

\author{
Dan Zheng ${ }^{1,2}$, Zhiwei Zhou ${ }^{3, *}$, Rui Yu ${ }^{3}$ and Menghu Wang ${ }^{1,2}$ \\ 1 School of Environmental and Biological Engineering, Wuhan Technology and Business University, \\ Wuhan 430065, China; zhengdan0707@163.com (D.Z.); wang.menghu@163.com (M.W.) \\ 2 Engineering and Technology Research Center of Hubei Province for Wastewater Reclamation, \\ Wuhan 430065, China \\ 3 College of Architecture and Civil Engineering, Beijing University of Technology, Beijing 100124, China; \\ bjutyu95@163.com \\ * $\quad$ Correspondence: zhouzw@bjut.edu.cn; Tel.: +86-10-67391726
}

Citation: Zheng, D.; Zhou, Z.; Yu, R.; Wang, M. Characteristics of

Ultrasonically Enhanced

Low-Temperature Thermal

Regeneration of Powdered Activated

Carbon: A Case Study of Acetone and

Aniline. Water 2021, 13, 1298.

https://doi.org/10.3390/w13091298

Academic Editor: Christos S. Akratos

Received: 18 March 2021

Accepted: 3 May 2021

Published: 6 May 2021

Publisher's Note: MDPI stays neutral with regard to jurisdictional claims in published maps and institutional affiliations.

Copyright: (c) 2021 by the authors. Licensee MDPI, Basel, Switzerland. This article is an open access article distributed under the terms and conditions of the Creative Commons Attribution (CC BY) license (https:/ / creativecommons.org/licenses/by/ $4.0 /)$.

\begin{abstract}
Effective regeneration of powdered activated carbon (PAC) is the key to reduce the operating cost of the PAC in wastewater treatment processes. In this study, volatile acetone and semi-volatile aniline were selected to investigate the regeneration characteristics of ultrasonically enhanced lowtemperature thermal process. The results showed that the regeneration efficiency of the PAC that had adsorbed aniline or acetone increased with the increase in ultrasonic power, and optimal value of frequency and regeneration times were determined. The concentration and properties of organic solvents had a significant influence on the ultrasonic regeneration process. With the increase in heating temperature and regeneration time, the regeneration efficiency increased, but the loss of mass of the saturated PAC increased noticeably. With the combination of ultrasonic treatment in a solvent with low temperature heating, the PAC regeneration efficiency was successfully improved, and the PAC mass loss rate was noticeably reduced. The microjet, shock wave, and cavitation effects produced by ultrasonic treatment restored the specific surface area of the PAC, expanded its mesopore volume, and increased the pore diameter. A reasonable selection of the regeneration solution and optimization of the ultrasonic treatment conditions could create favorable conditions for subsequent low temperature thermal regeneration.
\end{abstract}

Keywords: powdered activated carbon; low-temperature thermal regeneration; ultrasound; volatile and semi-volatile organic pollutant

\section{Introduction}

As a broad-spectrum adsorbent, powdered activated carbon (PAC) can adsorb various pollutants in water, such as refractory organic compounds [1], humic acid [2], microbial metabolites [3], and heavy metals [4]. It is widely used for the purification of source water [5], emergency water treatment [6], and advanced treatment of printing-dyeing wastewater [7]. Due to the fact that PAC is a costly material [8], it is usually regenerated and recycled when it is used in a water or wastewater treatment process. In this context, efficient regeneration technologies are required to achieve effective PAC recycling, improve the efficiency of the use of the PAC, and reduce the process operation cost [9].

Currently, methods for the regeneration of activated carbon include biological regeneration [8], thermal regeneration [10-12], ultrasonic regeneration [13-15], solvent regeneration, and advanced oxidation regeneration [16]. The thermal regeneration method is subdivided into low-temperature $\left(105^{\circ} \mathrm{C}-200{ }^{\circ} \mathrm{C}\right)$ and high-temperature $\left(450{ }^{\circ} \mathrm{C}-900{ }^{\circ} \mathrm{C}\right)$ methods. The high-temperature thermal regeneration method desorbs, carbonizes, oxidizes, and decomposes the adsorbate by heating is efficient and convenient, but has shortcomings in terms of high energy consumption and great carbon loss $[10,11]$. The 
ultrasonic regeneration method is mainly suitable for the regeneration of the PAC used for physical adsorption, and its primary shortcoming is that its regeneration process is incomplete [15]. When inorganic or organic solvents are used for regeneration (the solvent regeneration method), the loss of the PAC is less. The solvent regeneration method is suitable for reversible adsorption, especially for adsorption of organic matter with a high concentration and a low boiling point [14]. However, the solvent regeneration method has the shortcomings of secondary pollution, incomplete regeneration, and micropore blockage, and the ability to adsorb can decline or be lost after repeated regenerations [10].

The ability to regulate and control the temperature, improve the efficiency, and reduce the carbon loss of thermal regeneration for a variety of potential pollutants is a crucial technical issue in the development of thermal regeneration technologies [10-12]. The low-temperature thermal regeneration process is suitable for the regeneration of the PAC used for physical adsorption, and has a good regeneration effect on PAC that has adsorbed aromatic compounds, lipids, and other compounds with low boiling points [14]. The temperature used in low-temperature thermal regeneration leads to quite different degrees of desorption for different pollutants. For some pollutants, the regeneration cycle has little influence on the regeneration efficiency above a certain regeneration temperature. Shah et al. [11] regenerated saturated granular active carbon that had adsorbed volatile organic compounds (acetone and butanone), and found that when the regeneration temperature was $80{ }^{\circ} \mathrm{C}$, the regeneration efficiency of acetone-adsorbed PAC after the first regeneration reached $95 \%$, and the regeneration efficiency remained unchanged after eight cycles of regeneration. However, the adsorption capacity of butanone gradually decreased after several regeneration cycles. Low-temperature thermal regeneration process could regenerate saturated PAC from biochemically treated coking wastewater at $250{ }^{\circ} \mathrm{C}$ in $30 \mathrm{~min}$, and the regeneration efficiency still reached $80.23 \%$ after 16 regeneration cycles [17].

Ultrasonic regeneration is a green physicochemical treatment technology [18]. Sonication causes a series of compression and rarefaction cycles leading to the generation of cavitation bubbles. Millions of these bubbles implode, yielding localized temperatures as high as $5000^{\circ} \mathrm{C}$, pressures of $100 \mathrm{MPa}$, and free radicals such as $\bullet \mathrm{OH}, \mathrm{HO}_{2} \bullet$ and $\mathrm{O} \bullet$ [19]. Compared with the carbon loss rate of the high-temperature thermal regeneration method $(5-10 \%)$, the carbon loss rate of ultrasonic regeneration $(<2 \%)$ is much lower. Ultrasonic cavitation can produce instantaneous high-temperature, high-pressure, strong shock waves, high-speed microjets, and other extreme physical effects on the local surface of the PAC. Studies on the regeneration of the PAC saturated with 4-chlorophenol (4-CP) [13], aniline [14] or chloramphenicol (CAP) [15] by ultrasound have been previously reported. However, when the ultrasonic regeneration method is used alone for the regeneration of 4-CP or CAP, which are difficult to desorb and degrade, the regeneration effect is not ideal.

By combining low-temperature thermal regeneration technology with ultrasonic regeneration technology, it is expected that the PAC regeneration efficiency can be improved and the carbon mass loss rate can be reduced. In this study, volatile acetone and semivolatile aniline were selected as representative pollutants to investigate the regeneration characteristics of the ultrasonic regeneration method, the low-temperature thermal regeneration method, and a combined approach that uses ultrasonic processing in an organic solvent as a pretreatment for the low-temperature thermal regeneration method. The mechanism of low-temperature thermal regeneration of ultrasonic-enhanced PAC was determined to provide technical support for the utilization and regeneration of the PAC.

\section{Materials and Methods}

\subsection{PAC Characteristics and Preparation of Saturated PAC}

The PAC used in the experiment was industrial coal activated carbon (Purchased from Junji Environmental Technology Co., Ltd., Wuhan, China, 200 mesh). It had an iodine value of $705.80 \mathrm{mg} / \mathrm{g}$, a methylene blue adsorption value of $174.71 \mathrm{mg} / \mathrm{g}$, a specific surface area of $624.40 \mathrm{~m}^{2} / \mathrm{g}$, a total pore volume of $0.44 \mathrm{~cm}^{3} / \mathrm{g}$, a mesopore volume of $0.34 \mathrm{~cm}^{3} / \mathrm{g}$, a micropore volume of $0.10 \mathrm{~cm}^{3} / \mathrm{g}$. Before the experiment, the PAC was washed with pure 
water and boiled 3 times to remove soluble impurities. The washed PAC was then dried at $105^{\circ} \mathrm{C}$ to a constant weight and stored in a dryer for later use.

The representative pollutants selected for the experiment were volatile acetone and semi-volatile aniline, with boiling points of $56.5^{\circ} \mathrm{C}$ and $184.4^{\circ} \mathrm{C}$, respectively. To achieve the saturated adsorption equilibrium on the PAC, $1.0 \mathrm{~g} / \mathrm{L}$ of washed and dried PAC was added to water containing either $500 \mathrm{mg} / \mathrm{L}$ of acetone or $100 \mathrm{mg} / \mathrm{L}$ of aniline. The mixture was stirred at room temperature $\left(25 \pm 2{ }^{\circ} \mathrm{C}\right)$ at $150 \mathrm{rpm}$ for $24 \mathrm{~h}$ to ensure that the PAC could reach adsorption equilibrium. The equilibrium adsorption capacity of the PAC for acetone and aniline was $230 \mathrm{mg} / \mathrm{g}$ and $58 \mathrm{mg} / \mathrm{g}$, respectively. The saturated PAC obtained after filtration was then put into a freeze dryer for the subsequent regeneration experiment.

\subsection{Regeneration Processes}

\subsubsection{Ultrasonic Regeneration Process}

The ultrasonic regeneration of the PAC saturated with acetone and aniline was carried out in an ultrasonic reactor (model KQ-200VDE, Kunshan Shumei Ultrasonic Instrument Co., Ltd., Suzhou, China), which has a maximum output power of $180 \mathrm{~W}$. Pure water $(1 \mathrm{~L})$ and $1.0 \mathrm{~g}$ of saturated PAC were put into the ultrasonic reaction tank. The water temperature was regulated to the required temperature by the temperature control system of the condenser tube and the ultrasonic reactor. The samples were stirred evenly by a motorized stirrer to avoid PAC precipitation during regeneration. The ultrasonic frequency $(20,40$, or $60 \mathrm{kHz})$, the power $(0-180 \mathrm{~W})$, and regeneration time (0 min-180 min) were adjusted as needed for each specific experiment.

The experiments with ultrasonic regeneration in organic solvent were carried out in the abovementioned ultrasonic reactor. The ultrasonic frequency was $40 \mathrm{kHz}$, the power was $180 \mathrm{~W}$, and the regeneration time was $60 \mathrm{~min}$ for aniline and $30 \mathrm{~min}$ for acetone. A $1.0 \mathrm{~g}$ sample of saturated PAC was added to $1 \mathrm{~L}$ of methanol or ethanol to investigate the influence of types and concentrations of the organic solvents on the ultrasonic regeneration effect.

\subsubsection{Low-Temperature Thermal Regeneration}

The low-temperature thermal regeneration experiments on PAC saturated with acetone or aniline were carried out in a tubular furnace (model OTF-1200X, Hefei Kejing, Hehei, China) under a nitrogen atmosphere. A $1.0 \mathrm{~g}$ sample of saturated PAC was placed in a quartz tube. The influence of regeneration temperature $\left(100^{\circ} \mathrm{C}-200{ }^{\circ} \mathrm{C}\right)$ and regeneration time (5 min-40 $\mathrm{min}$ ) on the PAC regeneration efficiency and the carbon mass loss rate were investigated under a nitrogen flow rate of $0.8 \mathrm{~mL} / \mathrm{min}-1.0 \mathrm{~mL} / \mathrm{min}$ and a heating rate of $20^{\circ} \mathrm{C} / \mathrm{min}$.

\subsubsection{Ultrasonic Pretreatment in Organic Solvent with Low-Temperature Thermal Regeneration}

In the combined regeneration process, ultrasonic treatment in organic solvent was used as a pretreatment for a subsequent low-temperature thermal regeneration. Ethanol and methanol were the organic solvents used for the regeneration of the PAC saturated with aniline and acetone, respectively. The parameters for the ultrasonic pretreatment in organic solvent were a power of $180 \mathrm{~W}$, a frequency of $40 \mathrm{kHz}$, an organic solvent concentration in water of 50\%, and a regeneration time of $60 \mathrm{~min}$. The low-temperature thermal regeneration used a nitrogen flow rate of $0.8-1.0 \mathrm{~mL} / \mathrm{min}$, and a heating rate of $20^{\circ} \mathrm{C} / \mathrm{min}$. The thermal regeneration temperature and time for the PAC saturated with aniline or acetone were $200{ }^{\circ} \mathrm{C}$ for $15 \mathrm{~min}$ or $150{ }^{\circ} \mathrm{C}$ for $30 \mathrm{~min}$, respectively.

\subsubsection{Degradation of Aniline by Ultrasound in Pure Water}

$50 \mathrm{mg} / \mathrm{L}$ aniline solution sample was prepared and put into an ultrasonic reaction tank. Under the conditions of $180 \mathrm{~W}$ and $40 \mathrm{kHz}$, the sample was degraded for $3 \mathrm{~h}$, and the concentration of aniline at different interval was measured to calculate the degradation 
rate of aniline. In addition, two $50 \mathrm{mg} / \mathrm{L}$ aniline solution samples were prepared, and $\mathrm{n}$-butanol and acetic acid were added to the water samples, respectively. The concentration of aniline under different degradation time was determined.

\subsection{Analysis Methods}

The concentration of aniline was analyzed by a colorimetric method using N-(1naphthyl) ethylenediamine as the chromogenic agent. The absorbance was measured at $545 \mathrm{~nm}$ on a UV-VIS spectrometer (UV-2600; SOPTOP, Yuyao, China). Acetone concentration was determined by UV-Vis spectrophotometer at $268 \mathrm{~nm}$. The specific surface area and pore volume of the PAC were analyzed using a nitrogen gas adsorption-desorption isotherm method with constant temperature gas adsorption at $77 \mathrm{~K}$ (Tristar II 3020M; MICROMERITICS, Norcross, USA), the sample was outgassed at $200^{\circ} \mathrm{C}$ for $8 \mathrm{~h}$ before the $\mathrm{N}_{2}$ adsorption-desorption experiment. The surface morphology of the PAC was analyzed with a scanning electron microscope (SEM, JEM-2100F, JEOL, Tokyo, Japan). Before SEM analysis, the PAC powder was uniformly pasted to a conductive adhesive and then sprayed with gold to improve the conductivity of the sample.

Equation (1) was used to calculate the equilibrium adsorption capacity $\mathrm{q}_{\mathrm{e}}(\mathrm{mg} / \mathrm{g})$ of the PAC, where $C_{0}$ and $C_{e}$ are the initial and equilibrium concentration of pollutants $(\mathrm{mg} / \mathrm{L})$, respectively, $\mathrm{v}$ is the volume of the adsorption/desorption solution $(\mathrm{L}), \mathrm{w}$ is the dosage of adsorbent used ( $\mathrm{g}$ ).

$$
\mathrm{q}_{\mathrm{e}}=\frac{\left(\mathrm{c}_{0}-\mathrm{c}_{\mathrm{e}}\right) \mathrm{V}}{\mathrm{w}}
$$

The regeneration efficiency (RE,\%) and the mass loss rate ( $\eta, \%)$ were calculated with Equations (2) and (3).

$$
\begin{aligned}
& \mathrm{RE}(\%)=\frac{\mathrm{q}_{\mathrm{d}}}{\mathrm{q}_{\mathrm{e}}} \times 100 \\
& \eta(\%)=\frac{\mathrm{W}_{\mathrm{t}}}{\mathrm{W}_{0}} \times 100
\end{aligned}
$$

where $q_{d}$ is the adsorption capacity of regenerated PAC $(\mathrm{mg} / \mathrm{g})$, and $\mathrm{W}_{0}$ and $\mathrm{W}_{\mathrm{t}}$ are the masses of the PAC before and after regeneration, respectively.

\section{Results and Discussion}

\subsection{Effect of Ultrasonic Regeneration}

With the increase in ultrasonic power, the regeneration efficiency of the PAC also increased. When the ultrasonic power was increased from 60 to $180 \mathrm{~W}$, the regeneration efficiency of the PAC adsorbed aniline increased from $45.60 \%$ to $62.29 \%$, and that of acetone increased from $30.89 \%$ to $45.30 \%$, respectively (Figure 1a). At the same power, the regeneration effect of the PAC which had adsorbed aniline was better, which was ascribed to the relatively lower adsorption equilibrium of aniline compared to acetone $(58 \mathrm{mg} / \mathrm{g}$ vs. $230 \mathrm{mg} / \mathrm{g}$ ). In the regeneration process, with the increase in ultrasonic power, the cavitation effect caused by ultrasonic energy was also strengthened continuously. The strong shock waves and high-speed microjets caused by ultrasonic cavitation repeatedly impacted the surface and pores of the PAC [20], which made more aniline and acetone molecules desorb from the PAC.

It can be seen from Figure $1 b$ that the regeneration efficiency of the PAC that had adsorbed aniline was higher at the same frequency compared to PAC that had adsorbed acetone. When the frequency was increased from 20 to $40 \mathrm{kHz}$, the regeneration efficiency of the PAC that had adsorbed aniline increased from $42.04 \%$ to $62.29 \%$, and that of the PAC had adsorbed acetone increased from $30.89 \%$ to $45.30 \%$. Increases of the frequency beyond $40 \mathrm{kHz}$ had little effect on the regeneration efficiency. When the ultrasonic frequency was $40 \mathrm{kHz}$, the regeneration efficiency of the PAC was optimal. Theoretically, with the increase in frequency, the complete cavitation period of the ultrasonic agitation is shortened and the diameter and collapse time of the cavitation bubbles are reduced [18]. As a result, the microjets and microbeams generated by ultrasonic vibrations at lower frequencies should 
act on small pores of activated carbon more effectively, and the regeneration efficiency should be improved. After increasing the frequency beyond $40 \mathrm{kHz}$, the regeneration rate remained basically the same. Due to the restriction of the experimental conditions, the increase in frequency could be continued, but it can be inferred that the increase in frequency may further improve the regeneration rate of the PAC.
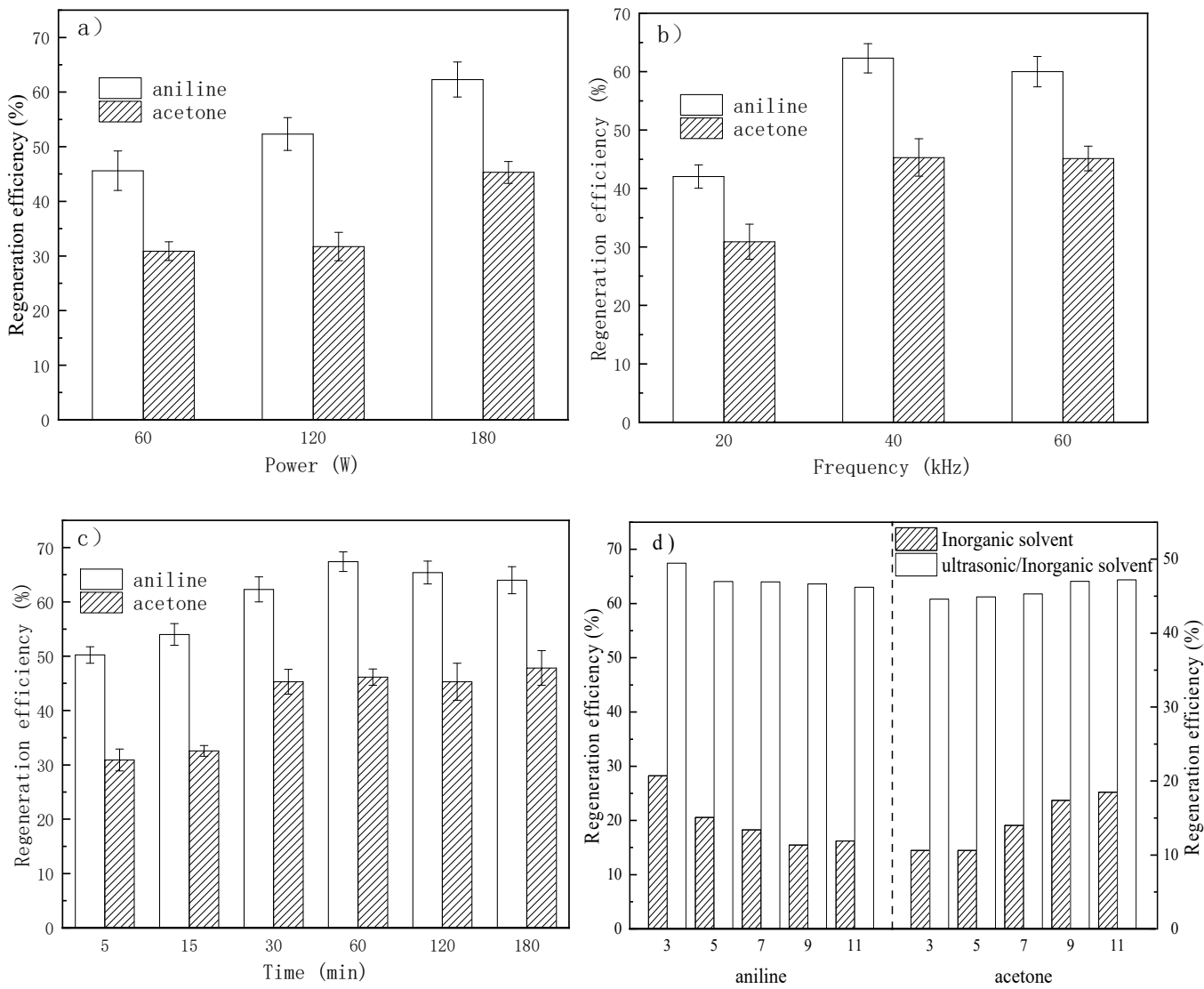

Figure 1. Factors affecting ultrasonic regeneration efficiency. (a) Power (frequency of $40 \mathrm{kHz}$, time of $180 \mathrm{~min}$ ). (b) Frequency (power of $180 \mathrm{~W}$, time of $180 \mathrm{~min}$ ). (c) Time (frequency of $40 \mathrm{kHz}$, power of $180 \mathrm{~W})$. (d) Effect of $\mathrm{pH}(3,5,7,9,11)$ on the regeneration efficiency (power of $180 \mathrm{~W}$, frequency of $40 \mathrm{kHz}$, time of $180 \mathrm{~min})$.

When the ultrasonic treatment time was increased from $5 \mathrm{~min}$ to $60 \mathrm{~min}$, the regeneration efficiency of the PAC which had adsorbed aniline or acetone increased from $50.23 \%$ to $67.4 \%$ or from $30.89 \%$ to $47.84 \%$, respectively (Figure 1c). When the ultrasonic treatment time was longer than $60 \mathrm{~min}$, the regeneration efficiency of the PAC remained basically the same with the prolong of the treatment time. When the ultrasonic treatment time exceeded $30 \mathrm{~min}$, the regeneration efficiency of the PAC that had adsorbed acetone basically did not change as the time was increased. After a certain duration of ultrasonic treatment, the concentration of cavitation bubbles in the solution was saturated. At this point, the hightemperature and high-pressure microjets and shock waves caused by cavitation bubble collapse could not further promote the desorption of the aniline or acetone. Additionally, the long ultrasonic treatment may also cause changes in the specific surface area of the PAC, thereby causing a decline in the adsorption ability of the PAC [13]. The results showed that the regeneration efficiency of the PAC could be improved by prolonging the ultrasonic treatment time properly, but after a certain regeneration time was reached, the regeneration efficiency of the PAC remained basically unchanged, and even decreased in some instances.

The effect of $\mathrm{pH}$ on the ultrasonic regeneration is shown in Figure 1d. Under the condition of mechanical stirring without ultrasound, the regeneration efficiency of the PAC 
adsorbed with aniline decreased slightly with the increase in $\mathrm{pH}$, while the regeneration efficiency of the PAC adsorbed with acetone increased slightly with the increase in $\mathrm{pH}$. After ultrasound regeneration with varied $\mathrm{pH}$, the regeneration efficiency of the PAC remained basically unchanged.

\subsection{Effect of Ultrasonic Treatment in Organic Solvent on Regeneration}

It can be seen from Figure 2 that during ultrasonic regeneration in methanol, the regeneration effect of the PAC that had adsorbed aniline was basically not influenced by the methanol concentration. When the methanol concentration was increased from $0 \%$ to $100 \%$, the regeneration efficiency only increased from $67.4 \%$ to $72 \%$. However, the regeneration efficiency of the PAC that had adsorbed acetone gradually increased with the increase in the methanol concentration. When the methanol concentration was increased from $0 \%$ to $50 \%$, the regeneration efficiency increased significantly from $45.30 \%$ to $62.32 \%$. When the methanol concentration was further increased, the regeneration efficiency of the PAC that had adsorbed acetone remained basically unchanged.
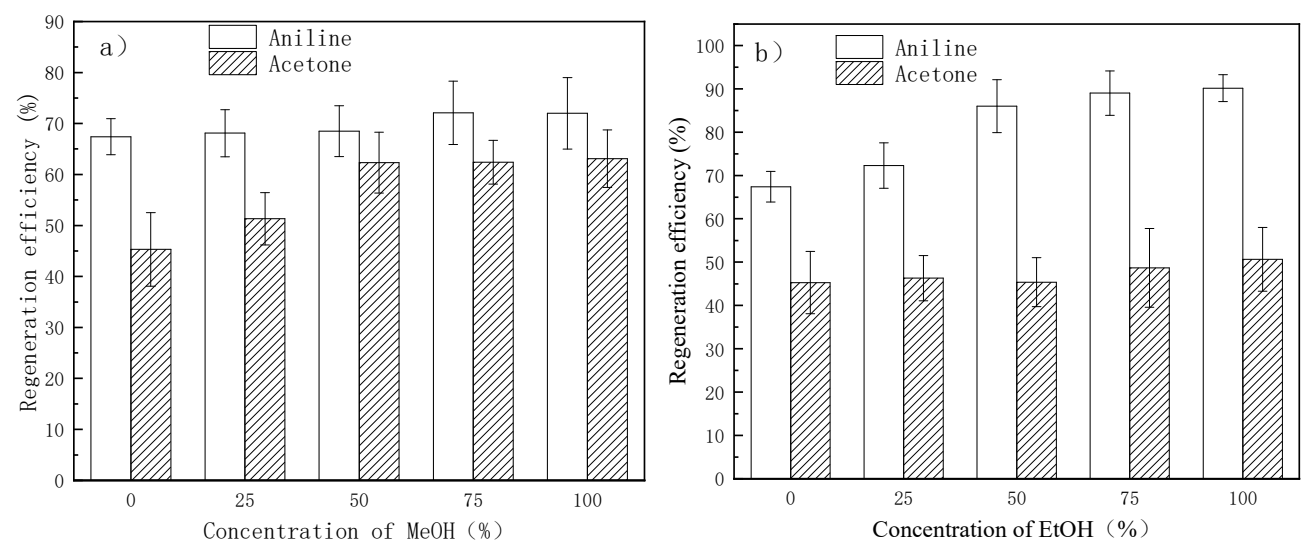

Figure 2. Effect of organic solvent and concentration on ultrasonic regeneration efficiency. Ultrasound power of $180 \mathrm{~W}$, frequency of $40 \mathrm{kHz}$, time of $180 \mathrm{~min}$. (a) Influence of methanol concentration. (b) Influence of ethanol concentration.

When the ultrasonic treatment in ethanol was used for regeneration, the regeneration efficiency of the PAC that had adsorbed acetone remained basically unchanged, indicating that ethanol could not promote the desorption from the PAC. When the ethanol concentration was increased from $0 \%$ to $100 \%$, the regeneration efficiency only increased from $45.30 \%$ to $50.62 \%$. The ethanol concentration had a great influence on the regeneration efficiency of aniline-adsorbed PAC. When the ethanol concentration was increased from $0 \%$ to $50 \%$, the regeneration efficiency of the PAC that had adsorbed aniline increased from $67.4 \%$ to $86.03 \%$, and the regeneration efficiency changed little when the ethanol concentration was increased beyond $50 \%$.

The instantaneous high-temperature and high-pressure microjets and shock waves caused by ultrasonic cavitation enhanced the contact between organic solvents and pollutants adsorbed on the PAC, which effectively promoted the desorption of pollutants from the PAC [15]. Due to the different polarities of the organic solvents, the desorption effects were different when different pollutants were adsorbed. Therefore, it is necessary to select the appropriate organic solvents for the specific pollutants to be removed.

\subsection{Effect of Low-Temperature Heating Regeneration}

As shown by the comparison of regeneration effects at different temperatures for $30 \mathrm{~min}$ of the low-temperature thermal regeneration in Figure 3. When the regeneration temperature was $150^{\circ} \mathrm{C}$, the regeneration efficiency of the PAC that had adsorbed aniline was only $61.15 \%$. When the regeneration temperature was increased from $150{ }^{\circ} \mathrm{C}$ to $200{ }^{\circ} \mathrm{C}$, the regeneration effect improved significantly, from $61.15 \%$ to $101.56 \%$, and the adsorption 
capacity of the PAC was completely restored. When the temperature was increased from 120 to $150{ }^{\circ} \mathrm{C}$, the regeneration efficiency of the PAC that had adsorbed acetone increased greatly from $45.3 \%$ to $89.37 \%$. When the temperature was further increased to $200{ }^{\circ} \mathrm{C}$, the adsorption capacity of the PAC was basically recovered to the level of the original PAC. With the increase in the thermal regeneration temperature, the mass loss rate of the PAC that had adsorbed aniline or acetone increased continuously. When the temperature was increased from $100{ }^{\circ} \mathrm{C}$ to $200{ }^{\circ} \mathrm{C}$, the mass loss rate of the PAC that had adsorbed aniline increased from $1.1 \%$ to $2.8 \%$, an increase of $154.5 \%$. When the temperature was increased from $120{ }^{\circ} \mathrm{C}$ to $200{ }^{\circ} \mathrm{C}$, the mass loss rate of the PAC that had adsorbed acetone increased from $2.4 \%$ to $3.6 \%$, an increase of $50 \%$.
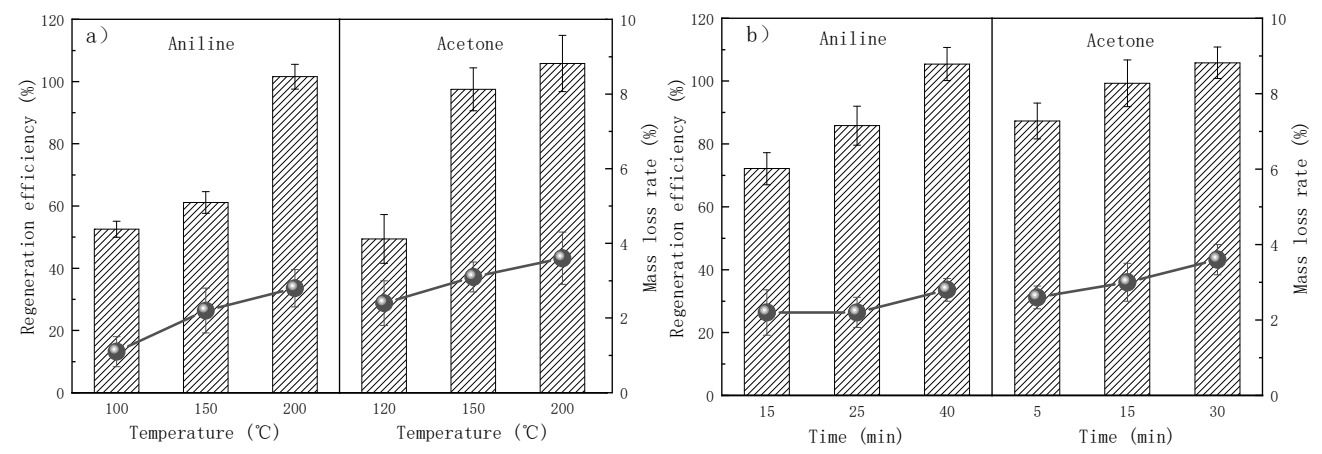

Figure 3. Effect of temperature and process time on low-temperature thermal regeneration efficiency. (a) Influence of temperature, time of $30 \mathrm{~min}$. (b) Influence of time, temperature of $200{ }^{\circ} \mathrm{C}$.

The regeneration efficiency of the PAC that had adsorbed aniline or acetone increased continuously as the time of the low-temperature thermal regeneration at $200{ }^{\circ} \mathrm{C}$ was increased, as shown in Figure $2 \mathrm{~b}$. When the regeneration time was increased from $15 \mathrm{~min}$ to $40 \mathrm{~min}$, the regeneration efficiency of the PAC that had adsorbed aniline increased from $72.16 \%$ to $105.42 \%$, an increase of $42.09 \%$. When the regeneration time was increased from $5 \mathrm{~min}$ to $30 \mathrm{~min}$, the regeneration efficiency of the PAC that had adsorbed acetone increased from $80.04 \%$ to $96.99 \%$, an increase of $21.18 \%$. With the increase in the thermal regeneration time, the mass loss rate of the PAC increased gradually. When the regeneration time was increased from $15 \mathrm{~min}$ to $40 \mathrm{~min}$, the mass loss rate of the PAC that had adsorbed aniline increased by $27.27 \%$, whereas when the regeneration time was increased from 5 min to $30 \mathrm{~min}$, the mass loss rate of the PAC that had adsorbed acetone increased by $38.46 \%$.

\subsection{Effect of a Combination of an Ultrasonic Pretreatment in Organic Solvent Followed by Low-Temperature Regeneration}

The effect of combined regeneration method, consisting of a combination of an ultrasonic pretreatment in an aqueous organic solvent solution followed by low-temperature heating, was noticeably better than that could be achieved with thermal regeneration alone, as shown in Figure 4. Compared with thermal regeneration for $15 \mathrm{~min}$, the regeneration efficiency of the PAC that had adsorbed aniline increased from $72.20 \%$ to $102.40 \%$, an increase of $41.83 \%$, indicating that the ultrasonic pretreatment in ethanol (50\% aq.) effectively improved the regeneration efficiency of the PAC. Similarly, the effect of the combined regeneration method on PAC that had adsorbed acetone was much better than that of thermal regeneration alone. It is worth noting that the adsorption capacity of the PAC that had adsorbed aniline could be completely regenerated after $40 \mathrm{~min}$ of thermal regeneration, while only 15 min was required to achieve the same effect by the combined regeneration method, which shortened the thermal regeneration time by $62.5 \%$, showing that ultrasonic pretreatment in aqueous ethanol could effectively shorten the subsequent time required for low-temperature thermal regeneration. Similarly, when ultrasonic pretreatment in methanol (50\% aq.) was used for the PAC that had adsorbed acetone, the effect of the subsequent thermal regeneration at $150{ }^{\circ} \mathrm{C}$ for $30 \mathrm{~min}$ was better than that of using ther- 
mal regeneration alone $\left(200{ }^{\circ} \mathrm{C}\right.$ for $\left.30 \mathrm{~min}\right)$, indicating that ultrasonic pretreatment in an aqueous solvent solution effectively reduced the temperature required for the subsequent low-temperature thermal regeneration. Ultrasonic cavitation was more likely to occur under the synergistic effects of ultrasonic vibration and organic solvents [20]. The high-speed microjets and high-pressure shock waves caused by cavitation impacted the PAC surface and pores more frequently, which promoted the desorption of aniline on PAC, effectively shortened the subsequent thermal regeneration time, and reduced the energy consumption of thermal regeneration.

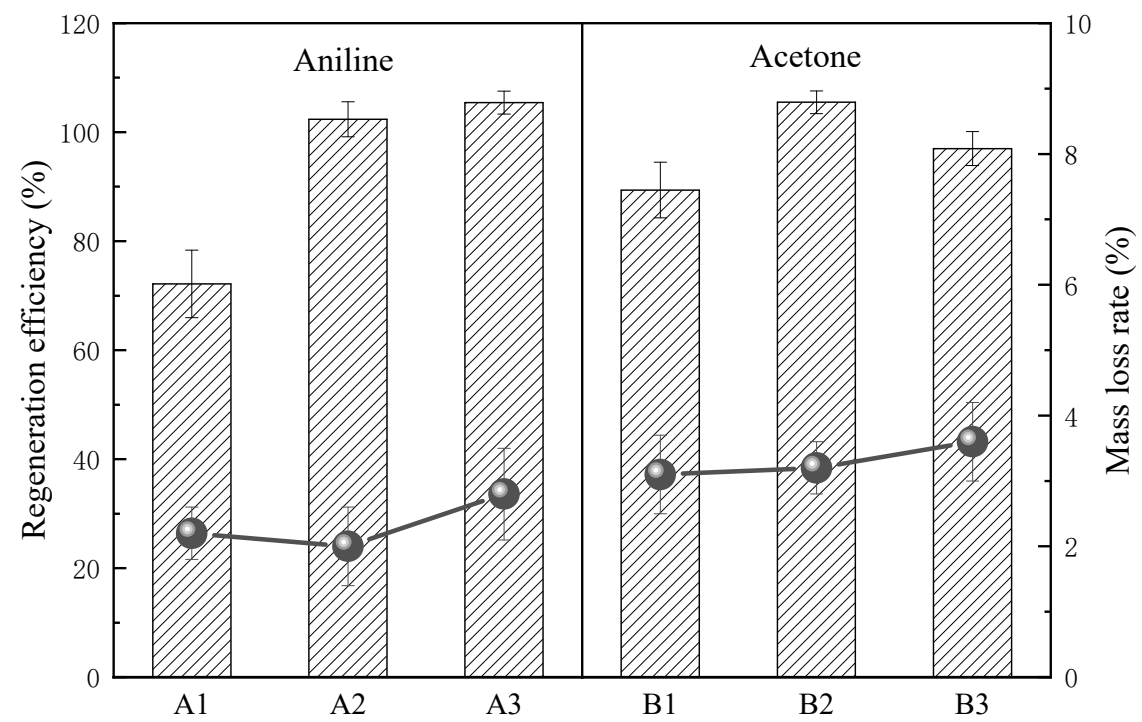

Figure 4. Regeneration efficiency of the combined method of an ultrasonic pretreatment with $50 \%$ aqueous solutions an organic solvent (ethanol $(\mathrm{EtOH})$ or methanol $(\mathrm{MeOH})$ ) followed by lowtemperature heating (A1: thermal regeneration, $200{ }^{\circ} \mathrm{C}, 15 \mathrm{~min}, \mathrm{~A} 2$ : ultrasonic/ethanol-thermal regeneration, $200{ }^{\circ} \mathrm{C}, 15 \mathrm{~min}, \mathrm{~A} 3$ : thermal regeneration, $200{ }^{\circ} \mathrm{C}, 40 \mathrm{~min}$, B1: thermal regeneration, $150{ }^{\circ} \mathrm{C}, 30 \mathrm{~min}, \mathrm{~B} 2$ : ultrasonic/methanol-thermal regeneration, $150{ }^{\circ} \mathrm{C}, 30 \mathrm{~min}$, B3: thermal regeneration, $\left.200{ }^{\circ} \mathrm{C}, 30 \mathrm{~min}\right)$.

The mass loss rate of the PAC regenerated by the combined regeneration method also decreased significantly. Compared with the mass loss rate by thermal regeneration for $15 \mathrm{~min}$, the mass loss rate of the PAC that had adsorbed aniline and then was treated by the combined regeneration method with low-temperature heating for 15 min decreased slightly from $2.2 \%$ to $2.0 \%$. Compared with the mass loss rate from thermal regeneration for $40 \mathrm{~min}$, the mass loss rate of aniline-saturated PAC by the combined regeneration method using aqueous ethanol with low-temperature heating for 15 min decreased significantly, from $2.8 \%$ to $2.0 \%$, a decrease of $28.6 \%$. Due to the decrease in the subsequent low-temperature thermal regeneration temperature, the carbon mass loss rate of the PAC pretreated by the ultrasonic process with aqueous methanol was obviously less than that of low-temperature thermal regeneration alone $\left(200^{\circ} \mathrm{C}\right.$ for $\left.30 \mathrm{~min}\right)$. The ultrasonic pretreatment with aqueous solvent efficiently desorbed aniline and acetone from the PAC, and the presence of organic solvent reduced the threshold value needed for ultrasonic cavitation.

\subsection{Regeneration Mechanism (Using Aniline as an Example)}

The pore structure parameters of the PAC are shown in Table 1 . The $\mathrm{N}_{2}$ adsorptiondesorption isotherms of the PAC before and after regeneration are shown in Figure 5. After adsorbing aniline, the specific surface area and the micropore volume of the PAC decreased. However, for saturated PAC after ultrasonic regeneration, the mesopore volume increased from $0.34 \mathrm{~cm}^{3} / \mathrm{g}$ to $0.37 \mathrm{~cm}^{3} / \mathrm{g}$, which indicated that the ultrasonic wave could change the pore structure of the PAC, resulting in an increase in mesopore volume. Compared with PAC regenerated by ultrasonic treatment alone, the specific surface area of the PAC 
regenerated by ultrasonic treatment with aqueous ethanol also increased significantly, from $505.83 \mathrm{~m}^{2} / \mathrm{g}$ to $582.04 \mathrm{~m}^{2} / \mathrm{g}$. Compared with ultrasonic regeneration alone, the ethanolenhanced ultrasonic regeneration could restore the specific surface area of the PAC more efficiently. Compared with unused PAC, the mesopore volume of the PAC regenerated by ultrasonic treatment increased from $0.34 \mathrm{~cm}^{3} / \mathrm{g}$ to $0.37 \mathrm{~cm}^{3} / \mathrm{g}$, which indicated that the ultrasonic action caused an expansion of the mesopores of the PAC. The expansion of the mesopores regenerated by the ethanol-enhanced ultrasonic regeneration was more obvious. Compared with unused PAC, the total pore volume and mesopore volume of the PAC regenerated by ultrasonic treatment in aqueous ethanol increased by $4.35 \%, 20.93 \%$, respectively. The microjets and shock waves caused by the collapse of cavitation bubbles during ultrasonic treatment played a major role in the PAC regeneration process. The highspeed microjets and high-pressure shock waves produced by cavitation bubble collapse mainly acted on the PAC surface and mesopores. Under the joint action of the ultrasonic treatment and the ethanol, the microjets and shock waves acted more intensely on the surface and mesopores of the PAC than when ethanol was not used.

Table 1. Pore structure parameters of the PAC.

\begin{tabular}{|c|c|c|c|c|}
\hline PAC Type & $\begin{array}{c}\text { BET Specific Surface } \\
\text { Area }\left(\mathrm{m}^{2} / \mathrm{g}\right)\end{array}$ & $\begin{array}{c}\text { Total Pore Volume } \\
\left(\mathrm{cm}^{3} / \mathrm{g}\right)\end{array}$ & $\begin{array}{l}\text { Micropore Volume } \\
\left(\mathrm{cm}^{3} / \mathrm{g}\right)\end{array}$ & $\begin{array}{c}\text { Mesopore Volume } \\
\left(\mathrm{cm}^{3} / \mathrm{g}\right)\end{array}$ \\
\hline Unused & 624 & 0.44 & 0.10 & 0.34 \\
\hline Saturated & 506 & 0.38 & 0.04 & 0.34 \\
\hline US regeneration & 537 & 0.41 & 0.04 & 0.37 \\
\hline US/EtOH regeneration & 582 & 0.46 & 0.03 & 0.43 \\
\hline Thermal regeneration & 627 & 0.49 & 0.09 & 0.41 \\
\hline US/EtOH-thermal regeneration & 602 & 0.44 & 0.12 & 0.32 \\
\hline
\end{tabular}
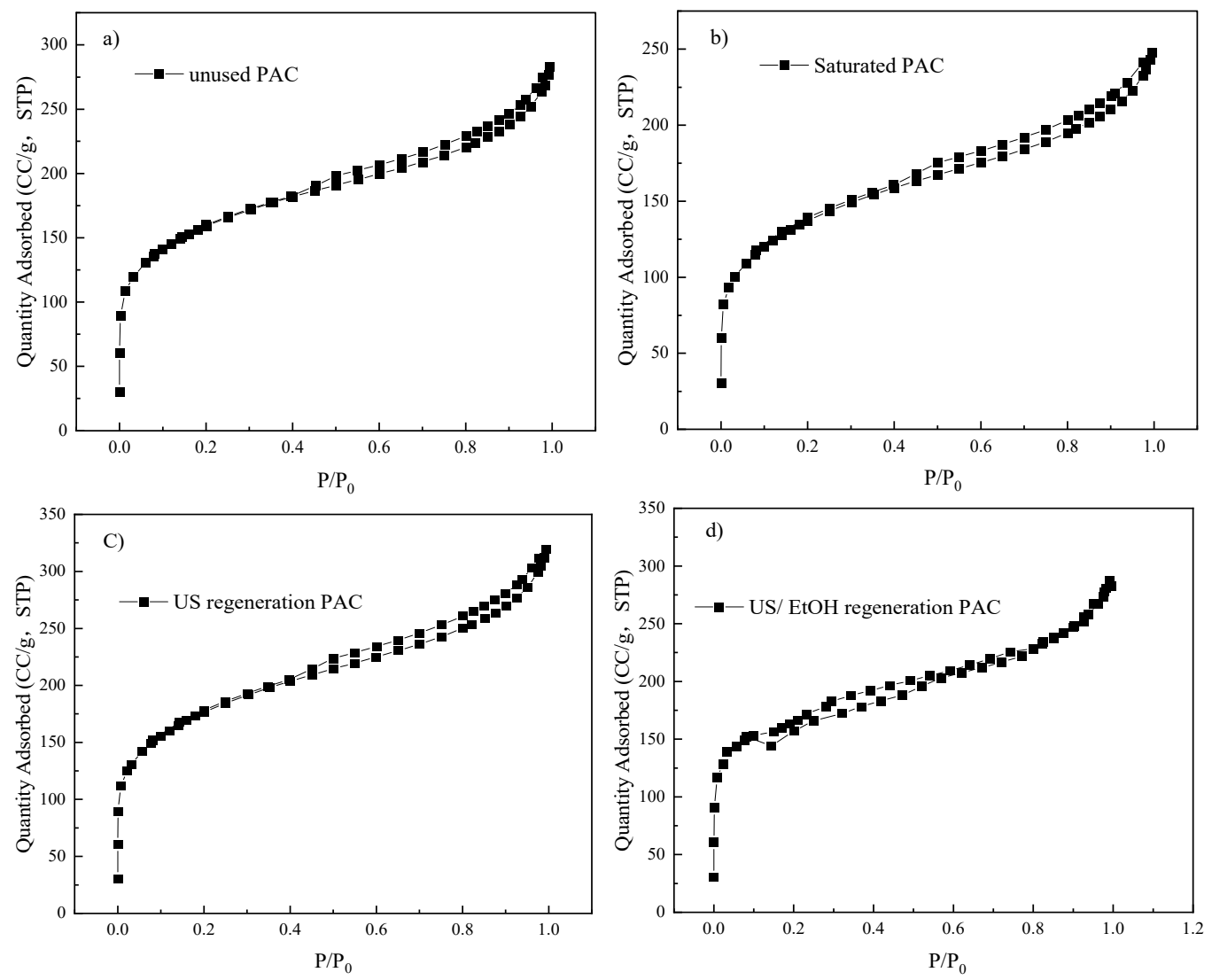

Figure 5. Cont. 

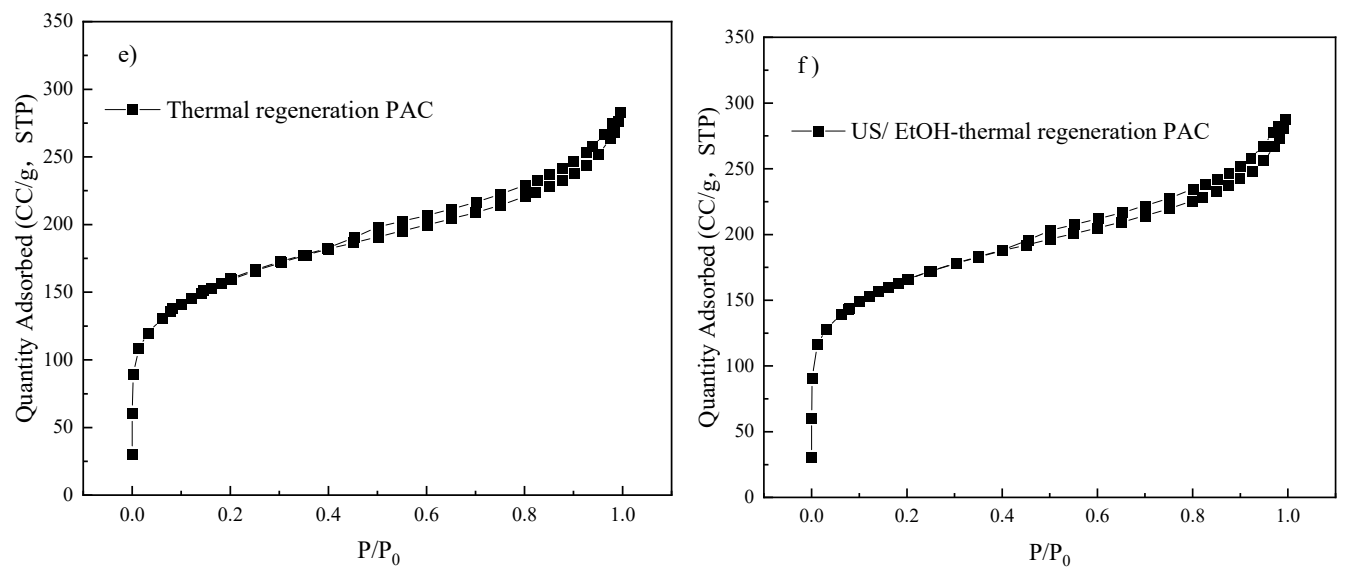

Figure 5. N2 adsorption-desorption isotherms of the PAC before and after regeneration. (a) Unused PAC. (b) PAC saturated with adsorbed aniline. (c) PAC regenerated by ultrasonic treatment. (d) PAC regenerated by ultrasonic treatment in ethanol. (e) Thermally regenerated PAC. (f) PAC treated by the combined regeneration process.

The specific surface area of thermally regenerated PAC $\left(627 \mathrm{~m}^{2} / \mathrm{g}\right)$ was basically the same as that of the unused PAC $\left(624 \mathrm{~m}^{2} / \mathrm{g}\right)$. In addition, the total pore volume increased by $11.4 \%$. The above results indicated that thermal regeneration could effectively restore the pore structure of the PAC. The specific surface area and total pore volume of thermally regenerated PAC all increased. The specific surface area of the PAC regenerated by the combined regeneration treatment of ultrasonic pretreatment in an aqueous ethanol solvent followed by low-temperature heating was restored to its initial levels. Both the unused and regenerated PAC had the same total pore volume, while the micropore volume of the regenerated PAC increased from $0.10 \mathrm{~cm}^{3} / \mathrm{g}$ to $0.12 \mathrm{~cm}^{3} / \mathrm{g}$. Micropores are the main area where adsorption occurs [21], so the adsorption capacity of the PAC could be restored efficiently by the combined regeneration treatment. Under the synergistic effect of ultrasonic vibration in the presence of the solvent, the microjets and shocks wave acted on the PAC surface and mesopores more frequently, resulting in an increase in mesopore volume and pore size [22], which created good conditions for subsequent thermal regeneration. Therefore, the combined regeneration method effectively improved the PAC regeneration efficiency, reduced the energy consumption, and lowered the mass loss rate of the PAC.

SEM micrographs of the PAC regenerated by different methods are shown in Figure 6. The surface of the unused PAC was smooth, but there were many impurities on its surface after the adsorption experiments, which was likely due to ultrafine particles resulting from the PAC erosion during the stirring of the suspension. After ultrasonic regeneration, the number of fine particles increased due to the further destruction of the activated carbon by the high-speed microjets and high-pressure shock waves caused by the ultrasonic treatment.

The contribution of ultrasonic cavitation to the degradation of aniline in water was studied at an ultrasonic power of $180 \mathrm{~W}$, a frequency of $40 \mathrm{kHz}$, an ultrasonic treatment time of $180 \mathrm{~min}$, and an aniline concentration of $50 \mathrm{mg} / \mathrm{L}$. It can be seen from Figure 7 that the degradation efficiency of aniline increased continuously with the increase in the ultrasonic treatment time. The degradation rate of aniline reached $17.2 \%$ when the ultrasonic treatment lasted for $180 \mathrm{~min}$, which indicated that aniline was partially degraded by the ultrasonic treatment. In a subsequent test, $\mathrm{n}$-butanol and acetic acid were added into water samples as $\bullet \mathrm{OH}$ inhibitors, where n-butanol could effectively remove free radicals in the interface area between the gas phase and cavitation bubbles and acetic acid mainly reacted with $\bullet \mathrm{OH}$ in the solution $[23,24]$. It can be seen that the addition of $\mathrm{n}$-butanol or acetic acid reduced the degradation efficiency of aniline from $17.2 \%$ to $6.6 \%$ or $16.0 \%$, respectively. The inhibitory effect of n-butanol was stronger than that of acetic 
acid, indicating that the degradation reaction mostly occurred at the interface area between cavitation bubbles.
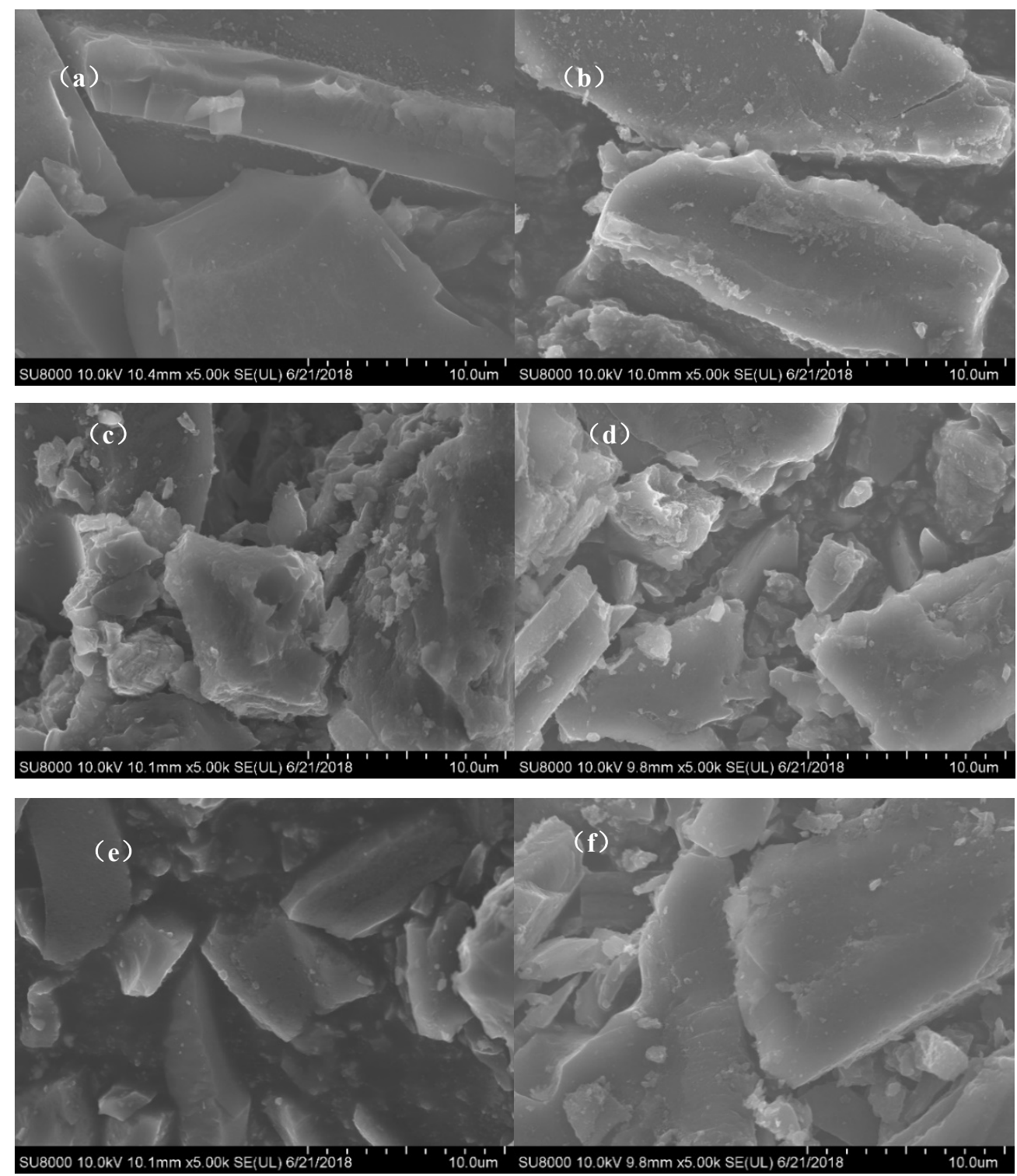

Figure 6. SEM of the PAC before and after different treatments. (a) Unused PAC. (b) PAC saturated with adsorbed aniline. (c) PAC regenerated by ultrasonic treatment. (d) PAC regenerated by ultrasonic treatment in ethanol. (e) Thermally regenerated PAC. (f) PAC treated by the combined regeneration process.

The aniline degradation by ultrasonic in the pure water medium was measured with gas chromatography-mass spectrometry [25], and the primary degradation product detected was azobenzene. Aniline has two degradation mechanisms: the formation of symmetrical azo bonds, and the formation of nitrobenzene [26]. Only azobenzene, a related product, was detected in the degradation product, which may be formed due to the formation of iminobenzene free radicals after aniline loses an electron when attacked by $\bullet \mathrm{OH}$. This kind of imino group is sensitive to substitution reactions, and azobenzene can be formed by the imino group through oxidation and two-electron coupling [27]. In the experiment, products such as nitrobenzene, phenol, and benzoquinone were not detected, indicating that azobenzene was not further degraded, and the ultrasonic cavitation effect could not completely decompose aniline. 


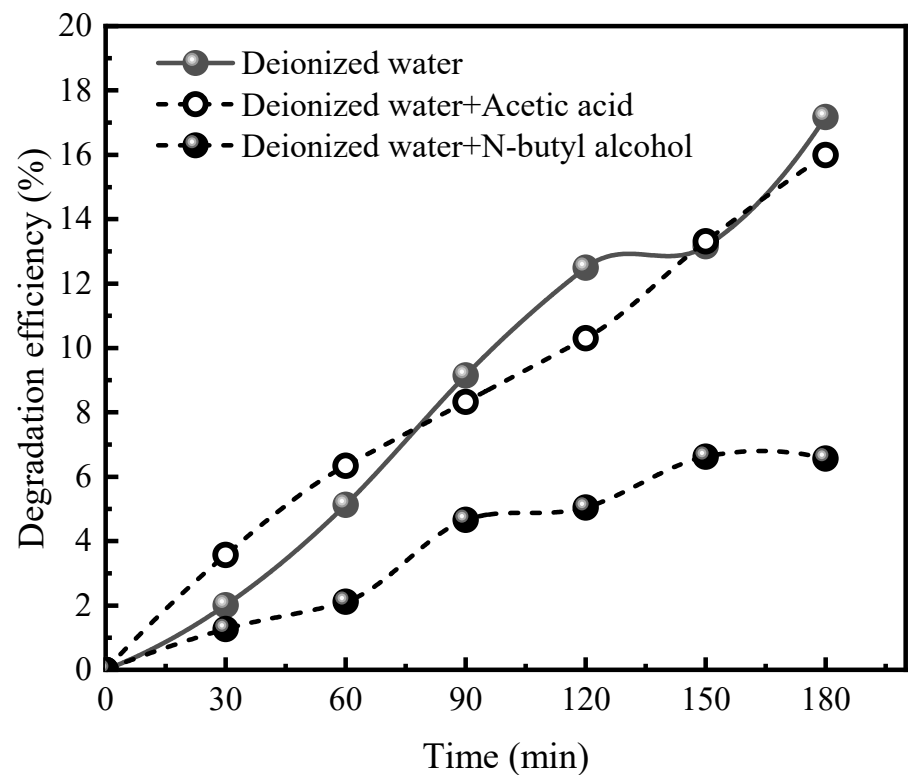

Figure 7. Degradation efficiency of aniline by ultrasonic cavitation.

\section{Conclusions}

(1) The regeneration effect of the PAC saturated with acetone or aniline can be improved with an increase in ultrasonic power, and the regeneration effect of aniline is better than that of acetone at the same power. There exists an optimum frequency $(40 \mathrm{kHz})$, at which the regeneration effect of both aniline and acetone is the best $(62.3 \%$ for aniline, $45.3 \%$ for acetone). When the regeneration time reaches a certain value (60 $\mathrm{min}$ for aniline, $30 \mathrm{~min}$ for acetone), the regeneration efficiency of the PAC is basically unchanged, and even decreases. The concentration and properties of organic solvents significantly affect the ultrasonic regeneration of the PAC saturated with aniline or acetone. The regeneration efficiency of both acetone- and aniline-adsorbed PAC increases with the increase in the ethanol concentration, reaching a maximum regeneration efficiency of $86.0 \%$.

(2) With the increase in the heating temperature and the regeneration time, the regeneration efficiency of the PAC saturated with aniline or acetone increases, and the mass loss of the PAC increases noticeably. At $200{ }^{\circ} \mathrm{C}$, when aniline- and acetone-adsorbed PAC are thermally regenerated for $40 \mathrm{~min}$ and $30 \mathrm{~min}$, respectively, the adsorption ability of the PAC in both cases can be restored to its original level.

(3) Under a condition of $100 \%$ regeneration efficiency, the ultrasonic pretreatment in aqueous ethanol can decrease the thermal regeneration time of aniline-adsorbed PAC from $40 \mathrm{~min}$ to $15 \mathrm{~min}$ and reduce the mass loss rate by $28.6 \%$. The ultrasonic pretreatment in aqueous methanol can reduce the thermal generation temperature of acetone-adsorbed PAC from $200^{\circ} \mathrm{C}$ to $150^{\circ} \mathrm{C}$. The combined regeneration process of an ultrasonic pretreatment in an aqueous organic solvent solution followed by low-temperature heating can effectively improve the PAC regeneration efficiency, lower the energy consumption, and reduce the PAC mass loss rate.

(4) The ethanol-enhanced ultrasonic regeneration of aniline-adsorbed PAC can effectively restore the specific surface area of the PAC, expand the mesopore volume, and increase the pore size, which makes the surface morphology of the PAC coarser. However, with the combined regeneration treatment, PAC agglomeration can be avoided and there are fewer impurities on the surface of the PAC, which are all related to the microjets and shock waves of the cavitation caused by ultrasonic agitation. The degradation efficiency of aniline in water by ultrasonic cavitation and $\bullet \mathrm{OH}$ mostly occurred at the interface area between cavitation bubbles reached $17.2 \%$, and the primary degradation product was azobenzene.

(5) The characteristics and the adsorption processes of organic compounds with low boiling points are quite different. Therefore, it is necessary to select the regeneration solu- 
tion reasonably and optimize ultrasonic treatment conditions to create favorable conditions for low-temperature thermal regeneration of the PAC saturated with organic compounds with low boiling points.

Author Contributions: D.Z., R.Y. and M.W. conducted the experimental work and provided technical support for this work. Z.Z. supervised the laboratory work and led the research. All authors have read and agreed to the published version of the manuscript.

Funding: This research is jointly funded by the Hubei Natural science foundation (2018CFB333).

Institutional Review Board Statement: Not applicable.

Informed Consent Statement: Not applicable.

Data Availability Statement: The data presented in this study is available on request from the corresponding author.

Acknowledgments: The authors would like to acknowledge the efforts of Department of Science and Technology of Hubei Province for financing the project through Hubei Natural science foundation (2018CFB333). Authors also would like to thank everyone who contributed to this article, field, and laboratory work.

Conflicts of Interest: The authors declare no conflict of interest.

\section{References}

1. Guillossou, R.; Le Roux, J.; Brosillon, S.; Mailler, R.; Vulliet, E.; Morlay, C.; Nauleau, F.; Rocher, V.; Gaspéri, J. Benefits of Ozonation Before Activated Carbon Adsorption for the Removal of Organic Micropollutants From Wastewater Effluents. Chemosphere 2020, 245, 125530. [CrossRef]

2. Kurtoglu, A.E.; Atun, G. Competitive Adsorption of 2,4-Dichlorophenoxyacetic Acid Herbicide and Humic Acid Onto Activated Carbon for Agricultural Water Management. Desalin. Water Treat. 2016, 57, 25653-25666. [CrossRef]

3. Feng, C.; Jin, J.; Sun, L.; Zhang, Y.; Chen, X.; Zhang, X. Study On the Organics Adsorption Capacities of Powdered Activated Carbon and Activated Coke in Reclaimed Water. Desalin. Water Treat. 2017, 62, 200-207. [CrossRef]

4. Zhang, Z.; Wang, T.; Zhang, H.; Liu, Y.; Xing, B. Adsorption of Pb(II) and Cd(II) by magnetic activated carbon and its mechanism. Sci. Total Environ. 2021, 757, 143910. [CrossRef] [PubMed]

5. He, Q.; Zhong, L.; Wang, H.; Zou, Z.; Chen, D.; Yang, K. Odor Removal by Powdered Activated Carbon (Pac) in Low Turbidity Drinking Water. Water Supply 2016, 16, 1017-1023. [CrossRef]

6. Zheng, T.; Du, Z.; Cao, H.; Jiang, J.; Zheng, W.; Tang, S.; Wang, N.; Wang, P. Development of a Novel Mobile Industrial-Scale Fluidized Adsorption Process for Emergency Treatment of Water Polluted by Aniline: CFD Simulation and Experiments. Adv. Powder Technol. 2016, 27, 1576-1587. [CrossRef]

7. Gürses, A.; Yalvaç, D.; Güneş, K.; Şahin, E.; Açıkyıldız, M. The Adsorption-Desorption Mechanisms on the Powdered Activated Carbon (Pac) of an Anionic Textile Dye (Rby 3Gl). Desalin. Water Treat. 2017, 70, 134-138. [CrossRef]

8. Gustafsson, A.; Hale, S.; Cornelissen, G.; Sjöholm, E.; Gunnarsson, J.S. Activated carbon from kraft lignin: A sorbent for in situ remediation of contaminated sediments. Environ. Technol. Innov. 2017, 7, 160-168. [CrossRef]

9. Shen, L.; Wang, W.; Li, T.; Cui, Y.; Wang, B.; Yu, G.; Wang, X.; Wei, D.; Xiao, J.; Deng, S. Powdered activated coke for COD removal in the advanced treatment of mixed chemical wastewaters and regeneration by Fenton oxidation. Chem. Eng. J. 2019, 371, 631-638. [CrossRef]

10. Ledesma, B.; Román, S.; Álvarez-Murillo, A.; Sabio, E.; González-García, C.M. Fundamental Study on the Thermal Regeneration Stages of Exhausted Activated Carbons: Kinetics. J. Therm. Anal. Calorim. 2014, 115, 537-543. [CrossRef]

11. Shah, I.K.; Pre, P.L.; Alappat, B.J. Effect of thermal regeneration of spent activated carbon on volatile organic compound adsorption performances. J. Taiwan Inst. Chem. Eng. 2014, 45, 1733-1738. [CrossRef]

12. Chiang, P.C.; Wu, J.S. Evaluation of Chemical and Thermal Regeneration of Activated Carbon. Water Sci. Technol. 1989, 21, 1697-1700. [CrossRef]

13. Zhang, T.T.; Yang, Y.L.; Li, X.; Wang, N.; Zhou, Z. Regeneration of 4-Chlorophenol from Spent Powdered Activated Carbon by Ultrasound. Environ. Sci. Pollut. Res. 2019, 26, 9161-9173. [CrossRef] [PubMed]

14. Yu, R.; Li, X.; Yang, Y.; Zhang, T.; Zhou, Z. Enhanced Desorption Performance of Aniline-Saturated Powdered Activated Carbon Using Ultrasound Assisted with Ethanol. Desalin. Water Treat. 2020, 190, 267-278. [CrossRef]

15. Zhang, T.T.; Yang, Y.L.; Li, X.; Jiang, Y.; Fan, X.; Du, P.; Li, H.; Wang, N.; Zhou, Z. Adsorption Characteristics of Chloramphenicol onto Powdered Activated Aarbon and Its Desorption Performance by Ultrasound. Environ. Technol. 2021, 42, 571-583. [CrossRef] [PubMed]

16. Plakas, K.V.; Karabelas, A.J. A Study on Heterogeneous Fenton Regeneration of Powdered Activated Carbon Impregnated with Iron Oxide Nanoparticles. Global NEST Int. J. 2016, 18, 259-268. 
17. Hu, L.; Zhao, D.; Yang, H.; Ma, J. The Application of Powdered Activated Carbon in Advanced Treatment of Coking Wastewater and Its Regeneration. Environ. Protec. Technol. 2016, 22, 41-44.

18. Pokhrel, N.; Vabbina, P.K.; Pala, N. Sonochemistry: Science and Engineering. Ultrason. Sonochem. 2016, 29, 104-128. [CrossRef] [PubMed]

19. Mason, T.J.; Tiehm, A. Advanced in Sonochemistry Volume 6-Ultrasound in Environmental Protection; Lightning Source UK Ltd.: Milton Keynes, UK, 2001.

20. Hamdaoui, O.; Naffrechoux, E.; Tifouti, L.; Pétrier, C. Effects of Ultrasound on Adsorption-Desorption of P-Chlorophenol on Granular Activated Carbon. Ultrason. Sonochem. 2003, 10, 109-114. [CrossRef]

21. Simpson, D.R. Biofilm Processes in Biologically Active Carbon Water Purification. Water Res. 2008, 42, 2839-2848. [CrossRef] [PubMed]

22. Liu, C.; Sun, Y.; Wang, D.; Sun, Z.; Chen, M.; Zhou, Z.; Chen, W. Performance and Mechanism of Low-Frequency Ultrasound to Regenerate the Biological Activated Carbon. Ultrason. Sonochem. 2017, 34, 142-153. [CrossRef] [PubMed]

23. Xiao, R.; Diaz-Rivera, D.; He, Z.; Weavers, L.K. Using Pulsed Wave Ultrasound to Evaluate the Suitability of Hydroxyl Radical Scavengers in Sonochemical Systems. Ultrason. Sonochem. 2013, 20, 990-996. [CrossRef] [PubMed]

24. Gultekin, I.; Ince, N.H. Ultrasonic Destruction of Bisphenol-a: The Operating Parameters. Ultrason. Sonochem. 2008, 15, 524-529. [CrossRef] [PubMed]

25. Chen, W.; Huang, C. Mineralization of Aniline in Aqueous Solution by Electro-Activated Persulfate Oxidation Enhanced with Ultrasound. Chem. Eng. J. 2015, 266, 279-288. [CrossRef]

26. Kumar, A.; Mathur, N. Photocatalytic Degradation of Aniline at the Interface of $\mathrm{TiO}_{2}$ Suspensions Containing Carbonate Ions. J. Colloid Interface Sci. 2006, 300, 244-252. [CrossRef]

27. Jiang, L.; Liu, L.; Xiao, S.; Chen, J. Preparation of a Novel Manganese Oxide-Modified Diatomite and its Aniline Removal Mechanism from Solution. Chem. Eng. J. 2016, 284, 609-619. [CrossRef] 